\title{
Soap opera reaps prize for its clean message
}

\section{WASHINGTON DC}

A Vietnamese soap opera is one of the winners of a World Bank competition for ideas to improve the livelihoods of people in the developing world.

The radio drama aims to teach Vietnamese rice farmers about sustainable farming, by weaving pest-management principles into the loves-and-hates storyline of a typical soap opera (see Nature 430, 284; 2004).

The response to the soap opera, which is based on the UK radio drama The Archers, has been overwhelming, says Monina Escalada, a research fellow at the International Rice Research Institute in Manila, the Philippines. Escalada organizes the writers and environmental scientists who team up to produce the scripts.

"We know farmers are listening," she adds. With the prize money, she says, the drama will be expanded to include other environmental issues, such as reducing straw-burning and conserving water.

The drama was one of more than 2,600 proposals submitted to the World Bank's Development Marketplace grant programme. The 78 finalists, which included individuals, governments, private foundations and academics from 42 countries, were invited to Washington DC last month to present their projects.

The theme of this year's competition was the environment, and 31 winning projects were chosen. They ranged from a Kenyan plan to pay the poor to collect charcoal that can be turned into clean-burning briquettes, to using solar-powered ovens in Costa Rica to sterilize hospital waste, which is normally dumped in landfills without treatment. The winners received up to $\$ 150,000$ each, with the remaining finalists each getting $\$ 5,000$.

The Development Marketplace started in 1998 as an internal competition "to get innovative, bottom-up ideas from staffers", explains John Wilton, vice-president of the bank's strategy, risk and finance group. But in 2000 it was opened to international entrants. ${ }^{\alpha} W e$ soon realized that it would be more exciting and useful to have the competition come from our client countries."

Since then, nearly US $\$ 35$ million has funded more than 570 projects in some 70 countries. Not all have gone on to do great things. But one of the big winners in the 2000 global contest was a South African proposal to harvest children's energy by installing water pumps masquerading as merry-go-rounds in village schools.

As the children play, water is pumped into a storage tank. HIV/AIDS awareness messages line two sides of the tank and the remaining space is sold for advertisements, which pay for the pumps' upkeep. There are now more than 400 play pumps in South Africa, and the idea is spreading throughout the continent as well as to south Asia and Latin America.

Observers welcome the competition's grassroots approach. "This is an excellent initiative to support local, innovative projects," says Manish Bapna, head of the Bank Information Centre, a watchdog of the World Bank.

But Bapna and others are also quick to point out that the investment involved is tiny compared with the money that they believe the World Bank spends on projects that are in the interests of big business, rather than local people or the environment.

"This reveals once again the inherent inconsistencies in World Bank activities," Bapna says. "It remains a lead financier for environmentally controversial oil, gas and mining projects."

Jessica Ebert

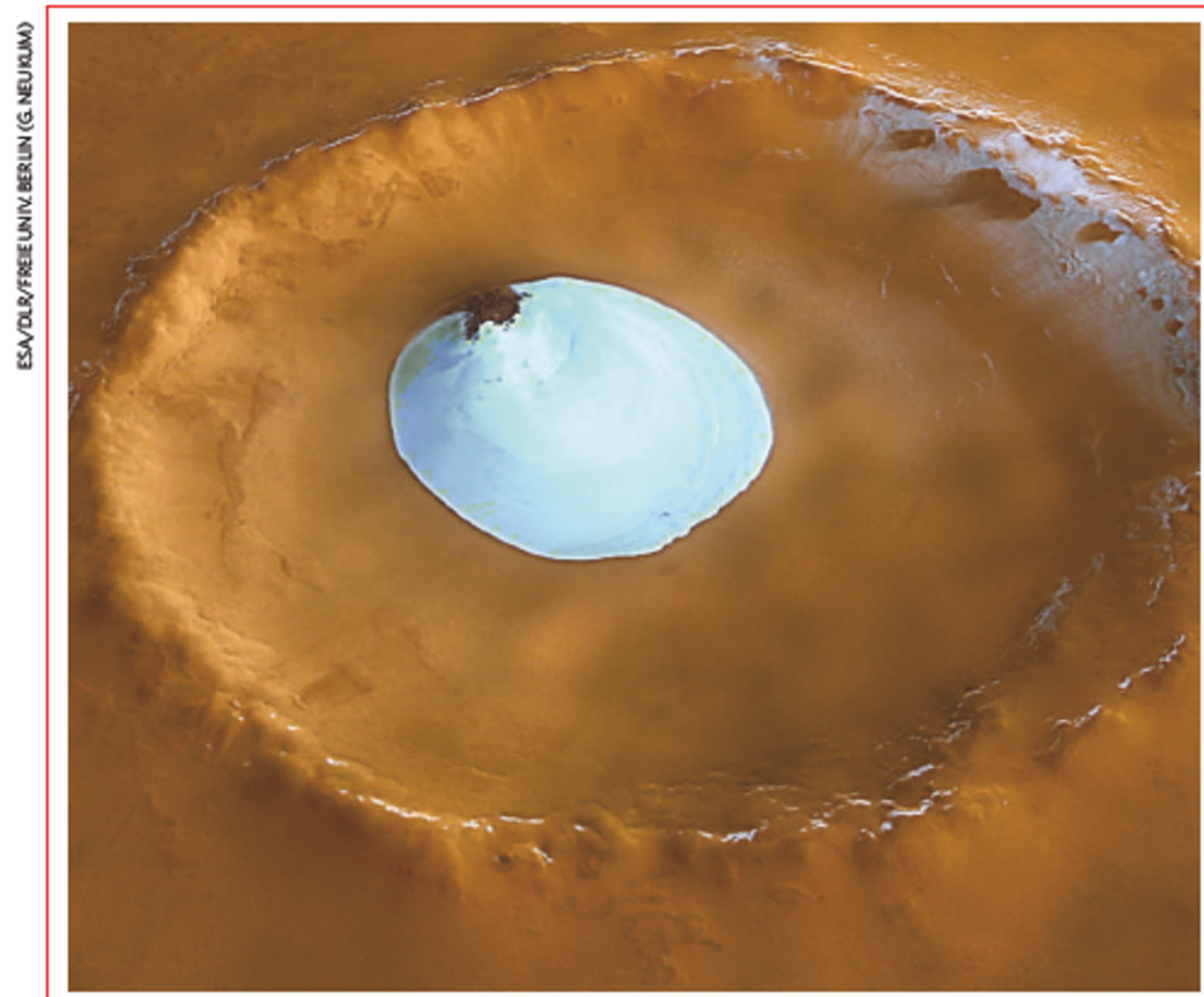

\section{SNAPSHOT}

\section{Sunlight on an icy martian crater}

This image from the Mars Express spacecraft shows a pocket of waterice nestling in a martian crater, bathed in the late martian summer sun.

The shadow of the crater's rim, which towers 300 metres over the surrounding plains, prevents the ice from vaporizing in the planet's thin atmosphere. A dusting of frost survives inside the rim to the upper right, while the sun glimmers on its south-facing outer edge.

The 35-kilometre-wide crater sits $70^{\circ}$ north of the martian equator, in a low-lying region known as Vastitas Borealis. Previous orbiters have spotted ice deposits in craters, but the High Resolution Stereo Camera on board the European probe is the first to return a threedimensional colour image of an icy spot. The ice may be up to 200 metres thick, and lies over a dune field that has formed in the sedimenton the crater's floor. The data were collected on 2 February, and this image was created for Nature last week. 